\title{
The interactions between OPEC oil price and sectoral stock returns: Evidence from China
}

\author{
Berna Kirkulak-Uludag ${ }^{\mathrm{a}, *}$, Omid Safarzadeh ${ }^{\mathrm{b}}$ \\ ${ }^{a}$ Dokuz Eylul University, Faculty of Business, Turkey \\ ${ }^{\mathrm{b}}$ Bilkent University, Turkey
}

\section{H I G H L I G H T S}

- Significant volatility spillover between OPEC oil and the Chinese stock returns.

- The transmission of volatility is more apparent from oil to stock returns.

- The observed spillover effects mainly come from the past shocks.

- Investors invest a larger portion in sectoral stocks than in OPEC oil.

\section{A R T I C L E I N F O}

\section{Article history:}

Received 10 February 2017

Received in revised form 11 December 2017

Available online 29 May 2018

\section{JEL classification:}

G12

F3

Q43

Keywords:

Volatility spillover

OPEC oil

China

VAR-GARCH model

\begin{abstract}
A B S T R A C T
This paper examines the volatility spillover between OPEC oil price and the Chinese sectoral stock returns from December 31, 2004 through October 17, 2014. In order to achieve this task, we used the VAR-GARCH model for the daily closing prices of six sectoral stock indices including: Construction, Machinery, Automobile, Military, Agriculture, and Financial indices. In addition, we analyzed the optimal weights and hedge ratios for oilstock portfolio holdings. The findings show significant volatility spillover between OPEC oil prices and the Chinese sectoral stock returns. The volatility spillover is unidirectional from oil to stock returns. The spillover effects mainly come from past shocks. The past oil shocks have negative and significant impact on the conditional volatility of Construction, Machinery, Automobile, Military and Agriculture stock indices. On the contrary, with the exception of the Military stock index, there is no significant impact of the past stock return shocks on the volatility of oil returns. Moreover, our findings for optimal weights and hedge ratios suggest that oil can improve the risk-adjusted performance of a well-diversified portfolio of stocks.
\end{abstract}

(C) 2018 Published by Elsevier B.V.

\section{Introduction}

Oil prices have always been volatile and consequently have a large impact on macroeconomic indicators such as GDP growth, inflation and interest rates [1,2]. Conventional wisdom holds a view that changes in oil prices are negatively correlated to macroeconomic indicators. Increase in oil prices puts pressure on production costs and reduces corporate earnings. The opposite situation is true when oil prices fall.

The role of oil in an economy is crucial not only for macroeconomic indicators but also for financial markets. Oil shocks affect stock markets through cash flows and through interest rates used in discounting the future cash flows of companies. The impact of oil shocks on stock markets depends on several factors including the country's net position in the crude oil

\footnotetext{
* Corresponding author.

E-mail addresses: berna.kirkulak@deu.edu.tr (B. Kirkulak-Uludag), omid.safarzadeh@bilkent.edu.tr (0. Safarzadeh).
} 
market, the source, and the direction of the oil shocks. The literature is inconclusive regarding the relationship between oil prices and stock markets. There have been a few studies that have made claims that the impacts of oil shocks on stock markets are insignificant [3-5]. However, a commonly held view shows that an upward trend in oil prices has a negative impact on stock markets, particularly in oil-importing countries [6-9].

In addition to the studies on the impact of oil prices on stock market returns, oil has received increasing attention due to its role in a diversified portfolio of stocks. In recent years, the popularity of commodities evokes the question - although oil is not a safe haven, can it serve as a hedge for portfolios made up of stocks? The more recent literature partially answers this question. It has been documented that oil has a hedging capacity and it can improve the risk-adjusted performance of a well-diversified portfolio of stocks in developed markets such as Europe and the United States [10,11]. However, the question of whether oil provides an effective hedge for emerging stock markets remains to be answered.

The motivation of this paper comes from the importance of oil for emerging economies, namely the Chinese economy. It is commonly known that oil prices are a barometer for the economic growth of a country. Similarly, China itself could be regarded as a barometer for world economic growth. China's heavy dependence on oil is an established fact, due to its rapid industrialization and urbanization over the past 35 years. In particular, after joining the WTO, China has accelerated its regulations in the oil market including permissions for non-state crude oil imports and the reduction in tariffs [12]. According to the USE [13], China surpassed the United States in 2013 as the world's largest net importer of oil due to its rising oil consumption and China's oil consumption growth accounted for approximately $43 \%$ of the world's oil consumption growth in 2014. Viewed from this angle, oil is immensely important for China and China is immensely important for the world.

The current paper attempts to investigate the volatility spillover between OPEC oil prices and the Chinese sectoral stock returns. The contributions of this paper are three fold. First, unlike several others in the literature reviewed, we use OPEC oil prices rather than WTI and Brent oil prices as oil benchmarks. The motivation for choosing OPEC oil prices is that the oil exported to Asia is priced against benchmark prices set in Abu Dhabi. However, the oil prices for the West are based on the West Texas Intermediate (WTI) or Brent benchmark prices which are usually at least 20 percent lower than the Arab benchmarks [14]. Since China heavily depends on OPEC oil and it imports $43 \%$ of its oil from Middle Eastern countries [15], it seems logical to choose OPEC oil prices as a proxy rather than WTI and Brent oil prices. Second, while investigating the shock and volatility transmission between oil and stock market returns, our focus is on sectoral stock returns. Instead of using national stock indices, which may not fully reflect the characteristics of several sectors, we concentrate on stock market sectors. There are very few studies that examine the relationship between oil and sectoral stock returns in China. In a more recent and comprehensive study, Caporale et al. [16] investigated the volatility spillover between oil and sectoral stock returns using ten sectoral indices including: Healthcare, Telecommunications, Basic Materials, Consumer Services, Consumer Goods, Industrials, Oil and Gas, Utilities, and Technology in China. However, the volatility spillover between oil and other sectoral indices has yet to be explored in the existing literature. Therefore, the current study attempts to fill this gap and uses six Chinese sectoral indices including: Construction, Machinery, Automobile, Military, Agriculture, and Financial indices. The use of these six sectoral stock indices can be complementary to previous results in the literature. ${ }^{1}$ Third, we analyzed optimal portfolio weights and hedge ratios for oil-stock portfolio holdings with respect to the VAR-GARCH results. To our knowledge, this study is the first of its kind that calculates the optimal weights and hedge ratios for oil-stock portfolio holdings in China.

Empirically, we use the daily closing prices of the OPEC oil and Chinese sectoral stock indices. We apply the VAR-GARCH method, developed by Ling and McAleer [17], to explore the volatility spillover between oil and the Chinese sectoral stock indices. In the literature, some researchers have already used the VAR-GARCH approach to investigate volatility spillover between oil and stock indices [18], and between precious metals and exchange rates [19]. The VAR-GARCH method allows us to give details about conditional volatility dynamics such as the direction of the volatility transmission and the impact of past shocks. It also provides an estimate of the model's parameters with fewer computational complications than other multivariate GARCH specifications. Moreover, the findings of the VAR-GARCH model are used to calculate the optimal weights and hedge ratios across the oil and sectoral stock indices.

Our findings show significant volatility spillover between OPEC oil prices and the Chinese sectoral stock indices over the period of 2004-2014. The transmission of volatility is apparent from oil to stock returns. The past oil shocks have had significant and negative impacts on the conditional volatility of the Chinese stock returns. On the contrary, with the exception of the Military index, the past Chinese stock return shocks have had no significant effect on the volatility of oil return. This result should be carefully interpreted by policy makers as well as by investors. As suggested by the findings that there is no significant volatility spillover from sectoral stock indices to OPEC oil. This result can be explained by the nature of the Chinese economy. In China, there is heavy government control over financial markets and regulations limit the investment activities of foreign and institutional investors in stock markets. In particular, the problems are more exacerbated, as the government owns majority stakes in listed companies [20]. These regulations have led to the Chinese stock markets not reflecting changes quickly in the economy and thus weakening the volatility spillover effects from stock markets to other markets.

\footnotetext{
1 We thank an anonymous referee for directing our attention to explain why we chose six sectoral stock indices. During our preliminary study, we applied VAR-GARCH model to various sectoral stock indices in China and obtained very similar results with those of Caporale et al. [16]. Therefore, we preferred to show the results of unexplored sectoral stock indices. We can provide the unreported results upon request.
} 
The portfolio analysis suggests that OPEC oil can be considered a dynamic and valuable asset to improve the performance of a well-diversified portfolio of sector stocks. Among all sector indices, the Military sector index with the lowest constant conditional correlation (CCC) estimate could be an opportunity for portfolio diversification and efficient risk management. The low interaction of the military sector with OPEC oil can be attributed to the strong presence of the Chinese government in the military industry. In particular, the majority of the military companies are state-owned and less than half of the military stocks are available to foreign investors [21].

The remainder of this paper is structured as follows. Section 2 introduces the relevant literature and Section 3 presents the data and methodology. Section 4 discusses the empirical findings and Section 5 provides a conclusion.

\section{Literature}

The early studies focus on the impact of oil price shocks on macroeconomic indicators. The seminal work of Hamilton [1] shows that oil prices strongly Granger cause the US economic growth and the unemployment rate. Subsequent studies examine the impact of oil shocks on other economies using different macroeconomic variables [2,22-24].

In comparison with the studies on the oil-macroeconomy nexus, the studies of the oil-stock market interactions were conducted later. Kling [25] and Jones and Kaul [6] were among the first economists to study the oil-stock relationship. Following their studies, many researchers attempted to investigate the relationship between oil and stock markets using different data sets and econometric methods (see [26-30] among others). In a comparative study, Jammazi [31] examines the relationship between changes in the stock prices and crude oil markets for five developed countries including: the U.S.A, Canada, Germany, Japan and the U.K. The findings of the paper suggest that the long-run crude oil-stock market relationship is interconnected in a negative unidirectional pattern, running from crude oil to stock market returns for oil-importing countries. In a more recent paper, Liu et al. [32] investigate the short-term and long-term relationships between the OVX (crude oil volatility index) and other important volatility indices, which are the VIX (stock market volatility index), EVZ (euro/dollar exchange rate volatility index) and GVZ (gold price volatility index). Their results suggest that among others, the stock market is the leading source of uncertainty whose changes are transmitted to the crude oil market.

Taking a step further, some papers have examined the relationship between oil and stock prices from a sectoral perspective. Among them, Malik and Ewing [33] address the volatility transmission between oil prices and five US equity sector indices (Financials, Industrials, Consumer Services, Health Care, and Technology). They apply bivariate GARCH models and document significant transmission between oil and sectoral stock returns. Arouri et al. [34] investigate the volatility spillover between oil and stock markets in Europe and in the United States at the sector-level. Their findings reveal the fact that the spillover is usually unidirectional from oil markets to stock markets in Europe, but bidirectional in the United States. Additionally, they conclude that oil risk exposures can be effectively hedged in portfolios of sector stocks. Sadorsky [35] investigates the volatility spillover between oil and stock prices of clean energy and technology companies listed on the NYSE. Using multivariate GARCH models (BEKK, CCC and DCC), the results suggest that the stock prices of clean energy companies correlate more resolutely with technology stock prices than with oil prices.

Concerning emerging markets, Basher and Sadorsky [27] study the impact of oil price changes on the stock markets of 21 emerging countries. They show substantial evidence of volatility spillover from oil price shocks to stock markets. In recent years, Awartani and Maghyereh [36] analyze the dynamic spillover of return and volatility between oil prices and the GCC stock markets during the time-period of 2004-2012. Their results indicate that the return and volatility transmissions are bidirectional. In particular, the return and volatility spillovers from the oil market to the GCC stocks are larger in magnitude in the aftermath of the 2007-2009 financial crisis. Using the jump-GARCH models, Fowowe [37] investigates the relationship between oil prices and stock returns on the Nigerian Stock Exchange. The findings indicate a negative but insignificant consequence of oil prices on stock returns in Nigeria. This suggests that there was an insufficient number of oil-related firms to assure a channeling of high oil prices to the stock market. In another study, Lin et al. [18] examine the volatility transmission between oil and stock market returns in Nigeria and Ghana by employing VAR-GARCH, VAR-AGARCH and DCCGARCH models. Their findings show that the transmission of volatility is more apparent from oil to stocks than from stocks to oil in Ghana. Further, they calculate the optimal weights and hedge ratios for the portfolios including oil in Nigeria and Ghana. Their findings show that hedging is more effective in Ghana. Focusing on the Saudi Arabia, Jouini [38] investigates the interdependencies between world oil prices and sectoral stock returns in the Saudi Stock Exchange. The empirical findings of the study show evidence of return and volatility transmission between oil prices and sectoral stock returns. However, in another recent study, Mensi et al. [39] analyze the dynamic linkages between commodity futures including oil and the Saudi stock market. They apply bivariate DCC-FIAPARCH models with and without structural breaks. Their findings show that there is an insignificant dynamic correlation between oil and the Saudi stock market. In a more recent study, Bouri [40] examines the return and volatility linkages between oil prices and the Lebanese stock market. The findings of the paper show that the linkages between oil and stock markets varied across the sub-periods due to the 2007-2009 financial crisis. Although the interrelationship between oil prices and the stocks increased during the financial crisis, it eased significantly in the post-crisis period.

In the wake of a growing oil demand in China, a burgeoning number of researchers examined the relationship between oil and the Chinese stock market returns (see [41-45], among others). For instance; Cong et al. [46] investigate whether or not oil price shocks affect the Chinese stock market. Their findings suggest that oil price shocks do not have a statistically significant impact on China's stock market indices. Zhang and Chen [47] examine the impacts of crude oil price shocks on the 
Chinese stock market. Using the EGARCH model, they arrive at the conclusion that the Chinese stock returns are correlated only with expected volatilities in world oil prices. Chang et al. [48] analyzed volatility spillover between oil returns and stock index returns of FTSE 100, NYSE, Dow Jones and S\&P from 1998 to 2009. Their results vary according to the methods that they used. Using the CCC model, they found a low correlation for returns across markets. VARMA-GARCH and VARMA-AGARCH models provide little evidence of independence between the crude oil and financial markets.

There have been very few attempts to investigate the impact of oil price changes on the sectoral stock returns in China. Li et al. [49] analyze the relationship between oil prices and the Chinese stock market at the sectoral level from July 2001 to December 2010. Using monthly data, they find that oil prices affect sectoral stock prices positively. This finding contradicts the theoretical expectations that stock prices will respond negatively to oil price changes. The authors attribute this positive relationship to the rise in leveraged investment in stocks. More recently, Caporale et al. [16] examine the impact of oil price uncertainty on Chinese sectoral returns. They use weekly data on ten sectoral indices, including: Healthcare, Telecommunications, Basic Materials, Consumer Services, Consumer Goods, Industrials, Oil and Gas, Utilities, and Technology. Their findings show that oil price volatility affects stock returns positively during periods characterized by demand-side shocks.

\section{Data and methodology}

\subsection{Data}

For our purposes, we used the daily closing spot prices of OPEC oil and the Chinese sector indices. The sectoral stock prices were taken from the Wind Financial Information Terminal. The OPEC oil prices were extracted from the DataStream International database. The sampling period was from December 31, 2004 through October 17, 2014. All prices are expressed in Chinese RMB. In some cases, the trading days of the OPEC oil do not overlap with the trading days of the Chinese stock markets. Therefore, we dropped some observations due to the mismatched trading days. Since we use daily data, the total number of observations remains quite large in spite of the omission of the mismatched trading days.

We compute oil and sectoral stock returns by taking the logarithms of the ratio between two successive prices.

$$
r_{t}=\operatorname{Ln}\left(P_{t} / P_{t-1}\right) \times 100
$$

\subsection{Methodology}

\section{Volatility Spillover}

The VAR-GARCH model was proposed by Ling and McAleer [17] and later applied by several researchers such as Chang et al. [48], Hammoudeh et al. [50], Arouri et al. [34], and Lin et al. [18]. The VAR-GARCH model is flexible enough to deal with conditional cross effects and volatility transmission between series with fewer computational complexities than other volatility spillover models. Similar to previous studies, we used VAR (1) -GARCH $(1,1)$. The optimal $p$ and $q$ parameters in the GARCH model were chosen according to AIC and BIC information criteria.

The VAR-GARCH model is based on the multivariate CCC-GARCH of Bollerslev [51] and it assumes symmetry in the effects of positive and negative shocks on conditional volatility.

The CCC specification underlying the multivariate conditional mean and conditional variance in returns is given as:

$$
Y_{t}=E\left(Y_{t} \mid F_{t-1}\right)+\varepsilon_{t} \quad \varepsilon_{t}=D_{t} \eta_{t}
$$

Where $y_{t}=\left(y_{1 t}, \ldots, y_{m t}\right)^{\prime}$ represents the vectors of sector-specific stock and oil returns at time $t ; D_{t}=\operatorname{diag}\left(\sqrt{h_{t}^{\text {Index }}}\right.$, $\left.\sqrt{h_{t}^{\text {OPEC }}}\right)=\left(\begin{array}{l}h_{t}^{\text {Index }} h_{t}^{\text {Index }, \text { OPEC }} \\ h_{t}^{\text {Index }, \text { OPEC }} h_{t}^{\text {OPEC }}\end{array}\right)$ is the matrix of conditional variances of stock and oil returns at time $t ; \eta_{t}=\left(\eta_{i, t}, \ldots, \eta_{m t}\right)^{\prime}$ shows a sequence of independently and identically distributed random vectors at time $t ; \vec{\varepsilon}_{t}=\left(\varepsilon_{i t}^{2}, \ldots, \varepsilon_{m t}^{2}\right)^{\prime}$ refers to the residual of the mean equations at time $t, F_{t}$ is the past information available to time $t$.

The Bollerslev's (1990) constant conditional correlation (CCC) model assumes that the conditional variance for each return, $h_{i t}, i=1, \ldots, m$, follows a univariate GARCH process:

$$
h_{i t}=\omega_{i}+\sum_{j=1}^{r} \alpha_{i j} \varepsilon_{i, t-j}^{2}+\sum_{j=1}^{s} \beta_{i j} h_{i, t-j}
$$

where $\alpha_{i j}$ represents the ARCH effects, or the short-run persistence of shocks to return $i$, and $\beta_{i j}$ represents the GARCH effects, or the contribution of shocks to return $i$ to long-run persistence, given as:

$$
\sum_{j=1}^{r} \alpha_{i j}+\sum_{j=1}^{s} \beta_{i j}
$$

The conditional correlation matrix of CCC is $\Gamma=E\left(\eta_{t} \eta_{t}^{\prime} \mid F_{t-1}\right)=E\left(\eta_{t} \eta_{t}^{\prime}\right)$, where $\Gamma=\left\{p_{i j}\right\}$ for $i, j=1, \ldots, m$. From (1), $\varepsilon_{t} \varepsilon_{t}^{\prime}=D_{t} \eta_{t} \eta_{t}^{\prime} D_{t}, D_{t}=\left(\operatorname{diag} Q_{t}\right)^{1 / 2}$, and $E\left(\varepsilon_{t} \varepsilon_{t}^{\prime} \mid F_{t-1}\right)=Q_{t}=D_{t} \Gamma D_{t}$, where $Q_{t}$ is the conditional covariance matrix. 


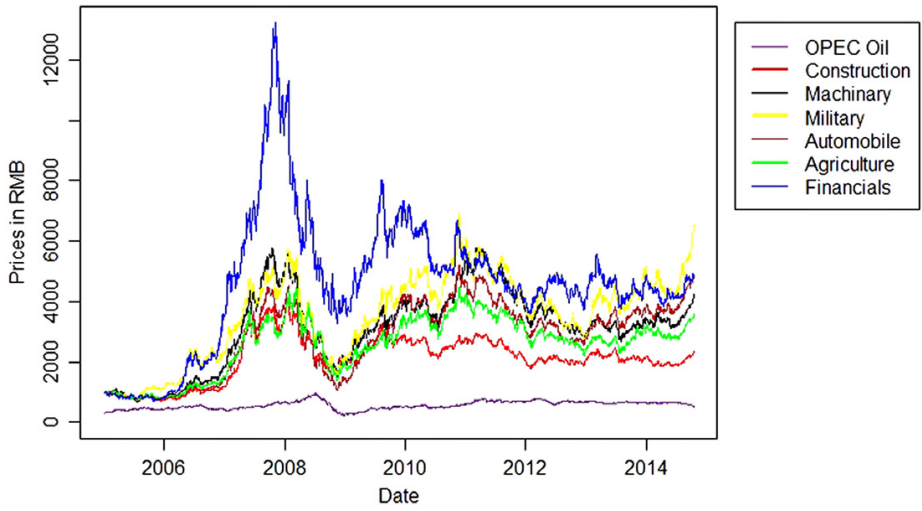

Fig. 1. Daily price changes for OPEC oil and sectoral stock indices.

The conditional correlation matrix is defined as $\Gamma=D_{t}^{-1} Q_{t} D_{t}^{-1}$, and each conditional correlation coefficient is estimated from the standardized residuals. In order to accommodate interdependencies, Ling and McAleer [17] proposed a VARMA specification of the conditional mean and the following specifications for the conditional variance:

$$
H_{t}=W+\sum_{i=1}^{r} A_{i} \vec{\varepsilon}_{t-i}+\sum_{j=1}^{s} B_{j} H_{t-j}
$$

where $H_{t}=\left(h_{1 t}, \ldots, h_{m t}\right)^{\prime}, \vec{\varepsilon}=\left(\varepsilon_{1 t}^{2}, \ldots, \varepsilon_{m t}^{2}\right)^{\prime}$, and $A_{i}$ for $i=1, \ldots, r$ and $B_{j}$ for $i=1, \ldots, s$ are $m \times m$ matrices defined as:

$$
A=\left(\begin{array}{ll}
\alpha_{s 1}^{2} & \alpha_{s 2}^{2} \\
\alpha_{01}^{2} & \alpha_{o 1}^{2}
\end{array}\right) \quad \text { and } \quad B=\left(\begin{array}{cc}
\beta_{s 1}^{2} & \beta_{s 2}^{2} \\
\beta_{o 1}^{2} & \beta_{o 2}^{2}
\end{array}\right)
$$

While the volatility across both markets is:

$$
\begin{aligned}
& h_{t}^{\text {Index }}=C_{\text {Index }}+\alpha_{\text {Index }}\left(\varepsilon_{t-1}^{\text {Index }}\right)^{2}+\beta_{\text {Index }} h_{t-1}^{\text {Index }}+\alpha_{\text {OPEC }}\left(\varepsilon_{t-1}^{\text {OPEC }}\right)^{2}+\beta_{O P E C} h_{t-1}^{\text {OPEC }} \\
& h_{t}^{\text {OPEC }}=C_{\text {OPEC }}+\alpha_{\text {OPEC }}\left(\varepsilon_{t-1}^{\text {OPEC }}\right)^{2}+\beta_{O P E C} h_{t-1}^{\text {OPEC }}+\alpha_{\text {Index }}\left(\varepsilon_{t-1}^{\text {Index }}\right)^{2}+\beta_{\text {Index }} h_{t-1}^{\text {Index }}
\end{aligned}
$$

Eqs. (7) and (8) show how volatility is transmitted across the oil and sectoral stock indices over the years through the cross values of error terms $\left(\varepsilon_{t-1}^{\text {OPEC }}\right)^{2}$ and $\left(\varepsilon_{t-1}^{\text {Index }}\right)^{2}$, which capture the direct effects of shock transmission. The lagged conditional volatilities, $h_{t-1}^{\text {OPEC }}$ and $h_{t-1}^{\text {Index }}$,indicate the transfer of risks between oil and sectoral stock indices. To make sure that the series are stationary, $\left|I_{2}-A L-B L\right|=0$ must be outside the unit circle. Where $L$ is a lag polynomial and $I_{2}$ is a $(2 \times 2)$ identity matrix, $A$ and $B$ are described in Eq. (6).

Let $p$ be the constant conditional correlation and the conditional covariance between OPEC oil and stock returns. The model is:

$$
h_{t}^{\text {Index, OPEC }}=p \times \sqrt{h_{t}^{\text {Index }}} \times \sqrt{h_{t}^{\text {OPEC }}}
$$

The parameters in VAR-GARCH models are obtained by maximum likelihood estimation (MLE) using a joint normal density of $\hat{\theta}=\operatorname{argmin}_{\theta} \frac{1}{2} \sum_{t=1}^{n}\left(\log \left|Q_{t}\right|+\varepsilon_{t}^{\prime} Q_{t}^{-1} \varepsilon_{t}\right)$. Where $\theta$ denotes the vector of parameters to be estimated in the conditional log-likelihood function, and $\left|Q_{t}\right|$ denotes the determinant of $Q_{t}$, the conditional covariance matrix. When $\eta_{t}$ does not follow a joint multivariate normal distribution, the above equation is defined as the Quasi-MLE (QMLE).

\section{Empirical findings}

Fig. 1 illustrates the dynamics of daily price changes for OPEC oil and sectoral stock indices. Both oil and sectoral stock prices are affected by the past shocks substantially. In particular, it is obvious from the figures that the 2007-2009 subprime financial crisis severely affected sectoral stock returns. The stock prices peaked in 2008 and declined sharply in 2009 . While the sectoral stock prices increased sharply in the beginning of 2008, the oil prices increased in the second half of 2008. In the aftermath of the global financial crisis, the trends have undergone tremendous changes. While the oil prices declined (even remained the same), the sectoral stock prices increased steadily.

Table 1 presents descriptive statistics. While the Military sector has the highest average return ( $8 \%)$, OPEC oil has the lowest average return (2.2\%). The volatility (measured by standard deviation) is the highest for Financials $(2.5 \%)$ and the 
Table 1

Descriptive statistics of return series.

\begin{tabular}{lllllll}
\hline Oil & Mean & St.Dev. & Skew. & Kurtosis & J-B & ARCH (5) \\
\hline OPEC & 0.022 & 0.016 & -0.127 & 23.116 & $39698.68^{* * *}$ & $130.81^{* * *}$ \\
\hline Index name & & & & & & \\
\hline Construction & 0.038 & 0.019 & -0.495 & 6.028 & $995.85^{* * *}$ & $243.25^{* * *}$ \\
Machinery & 0.063 & 0.020 & -0.465 & 5.170 & $546.92^{* * *}$ & $172.10^{* * *}$ \\
Automobile & 0.067 & 0.021 & -0.484 & 5.239 & $584.15^{* * *}$ & $235.75^{* * *}$ \\
Military & 0.080 & 0.023 & -0.439 & 4.668 & $548.98^{* * *}$ & $168.04^{* * *}$ \\
Agriculture & 0.056 & 0.021 & -0.534 & 5.318 & $639.36^{* * * *}$ & $57.76^{* * *}$ \\
Financials & 0.067 & 0.025 & 0.033 & 4.968 & $380.59^{* * *}$ & $292.84^{* * *}$ \\
\hline
\end{tabular}

Note: This table reports the descriptive statistics for return series. J-B (Jarque-Bera) test is used for normality. ARCH test is used for conditional heteroskedasticity. Ljung-Box is the empirical statistics for autocorrelation with five lags applied to raw returns. The codes of sectoral indices are as follows: CI005007.CI (Construction). CI005010.CI (Machinery). CI005013.CI (Automobile). CI005012.CI (Military and Defence). CI005020.CI (Agriculture). CI005022.CI (Financials without Banks). ${ }^{* * *}$ Significant at $1 \%$ level. ${ }^{* *}$ Significant at $5 \%$ level. ${ }^{*}$ Significant at $10 \%$ level.

Table 2

Correlation levels for return series.

\begin{tabular}{|c|c|c|c|c|c|c|c|}
\hline & OPEC & Cons. & Mach. & Auto & Milit. & Agri. & Finan. \\
\hline OPEC & 1.000 & & & & & & \\
\hline Construction & $0.112^{* * *}$ & 1.000 & & & & & \\
\hline Machinery & $0.131^{* * *}$ & $0.895^{* * *}$ & 1.000 & & & & \\
\hline Automobile & $0.091^{* * *}$ & $0.871^{* * *}$ & $0.915^{* * *}$ & 1.000 & & & \\
\hline Military & $0.120^{* * *}$ & $0.735^{* * *}$ & $0.801^{* * *}$ & $0.792^{* * *}$ & 1.000 & & \\
\hline Agriculture & $0.102^{* * *}$ & $0.835^{* * *}$ & $0.870^{* * *}$ & $0.858^{* * * *}$ & $0.758^{* * *}$ & 1.000 & \\
\hline Financials & $0.134^{* * *}$ & $0.692^{* * *}$ & $0.701^{* * *}$ & $0.681^{* * *}$ & $0.564^{* * *}$ & $0.602^{* * *}$ & 1.000 \\
\hline
\end{tabular}

Note: This table reports the pairwise Pearson correlation coefficients for log returns of the series. ${ }^{* * *}$ denotes statistical significance at $1 \%$ levels.

Table 3

Unit root test results.

\begin{tabular}{|c|c|c|c|c|c|c|}
\hline & \multicolumn{3}{|c|}{ With trends } & \multicolumn{3}{|c|}{ Without trends } \\
\hline & $\overline{\mathrm{ADF}}$ & PP test & KPSS & $\overline{\mathrm{ADF}}$ & PP test & KPSS \\
\hline OPEC & $-31.413^{* * *}$ & $-38.698^{* * *}$ & 0.1805 & $-31.389^{* * *}$ & $-38.698^{* * *}$ & 0.0695 \\
\hline Construction & $-33.973^{* * *}$ & $-46.679 * * *$ & 0.1795 & $-33.956^{* * *}$ & $-46.679^{* * *}$ & 0.0928 \\
\hline Machinery & $-34.021^{* * *}$ & $-44.969^{* * *}$ & 0.2303 & $-33.971^{* * *}$ & $-44.969^{* * *}$ & 0.1104 \\
\hline Automobile & $-34.164^{* * *}$ & $-44.712^{* * *}$ & 0.1327 & $-34.125^{* * *}$ & $-44.712^{* * *}$ & 0.1000 \\
\hline Military & $-33.090^{* * *}$ & $-44.456^{* * *}$ & 0.1424 & $-33.042^{* * *}$ & $-44.456^{* * *}$ & 0.0892 \\
\hline Agriculture & $-34.629^{* * *}$ & $-44.422^{* * *}$ & 0.1334 & $-34.603^{* * *}$ & $-44.422^{* * *}$ & 0.0747 \\
\hline Financials & $-33.937^{* * *}$ & $-48.074^{* * *}$ & 0.395 & $-33.865^{* * *}$ & $-48.074^{* * *}$ & 0.1204 \\
\hline
\end{tabular}

Note: The $1 \%$ critical values are -3.432 and -3.961 for the ADF and PP tests, respectively. ${ }^{* *}$ and ${ }^{* * *}$ denote statistical significance at the $5 \%$ and $1 \%$ levels, respectively.

lowest for OPEC oil (1.6\%). The skewness is negative for OPEC oil and the sectoral indices of Construction, Machinery, Automobile, Military and Agriculture. The skewness is positive for the sectoral stock index of Financials, suggesting that investors in Financials have a high probability for positive returns. The kurtosis is above three for all of the return series. This result indicates that all of the return series have leptokurtic distribution. The Jarque-Bera test rejects the null hypothesis of normal distribution. ARCH (5) test results show strong evidence of ARCH effects in all of the return series. As a result, the null hypothesis of no ARCH effect is rejected. Furthermore, the Ljung-Box Test shows that all of the return series are serially correlated. The information contained in past returns can be used for future return prediction.

Table 2 documents the unconditional correlation between the daily returns of sector indices and OPEC oil. When we pair OPEC oil with sector indices, the correlation coefficients are positive but generally low. The results reveal, while the highest correlation occurs between Financials and OPEC oil (0134), the lowest correlation occurs between the Automobile index and OPEC oil (0.091). It might be surprising to see a positive and high correlation between OPEC oil and sector indices. When oil prices increase, many companies have to spend more money to execute their business. The higher cost involved in the price of the products yields higher prices to the consumers. The positive correlation suggests that in recent years, commodity and stock prices move in the same direction as a consequence of more optimistic or more pessimistic expectations about the global economy. Both commodity and stock prices became more sensitive to the global economy rather than idiosyncratic and market-specific shocks [52].

Table 3 shows unit root test results. The stationary of the return series is tested using the following: Augmented Dickey and Fuller (ADF) [53], Philips and Perron (PP) [54], and Kwiatkowski et al. (KPSS) [55] tests. The null hypothesis of the unit root is rejected for ADF and PP tests. The findings of the KPSS test correspond with ADF and PP test results, indicating that the return series follows stationary processes.

Table 4 presents the results of the Granger Causality test. In order to understand how Chinese sector-specific stock indices are linked to OPEC oil, we use a Granger Causality test. The null hypothesis is accepted in many cases. The findings show that 
Table 4

Granger causality tests between returns of oil and sectors.

\begin{tabular}{|c|c|c|c|c|c|}
\hline Null hypothesis & Lags & $F$-value & Null hypothesis & Lags & $F$-value \\
\hline OPEC $\neq>$ Construction & 1 & 0.0270 & Construction $\neq>$ OPEC & 1 & 0.06574 \\
\hline OPEC $\neq>$ Machinery & 1 & $3.3104^{*}$ & Machinery $\neq>>$ OPEC & 1 & 0.23207 \\
\hline OPEC $\neq>$ Automobile & 1 & 2.3808 & Automobile $\neq>$ OPEC & 1 & 1.16310 \\
\hline OPEC $\neq>$ Military & 1 & 2.4008 & Military $\neq>$ OPEC & 1 & 0.83181 \\
\hline OPEC $\neq>$ Agriculture & 1 & 0.0231 & Agriculture $\neq>$ OPEC & 1 & 0.04613 \\
\hline OPEC $\neq>$ Financials & 1 & $4.1595^{* *}$ & Financials $\neq>>$ OPEC & 1 & 1.01681 \\
\hline
\end{tabular}

Note: The symbol " $\neq$ " means "does not Granger-cause." To select the order of lags for Granger causality test, we use AIC and SIC information criteria. ** and

*** denote statistical significance at the $5 \%$ and $1 \%$ levels, respectively.

Table 5

Estimates of VAR(1)-GARCH(1) model for OPEC oil and sectoral stock returns.

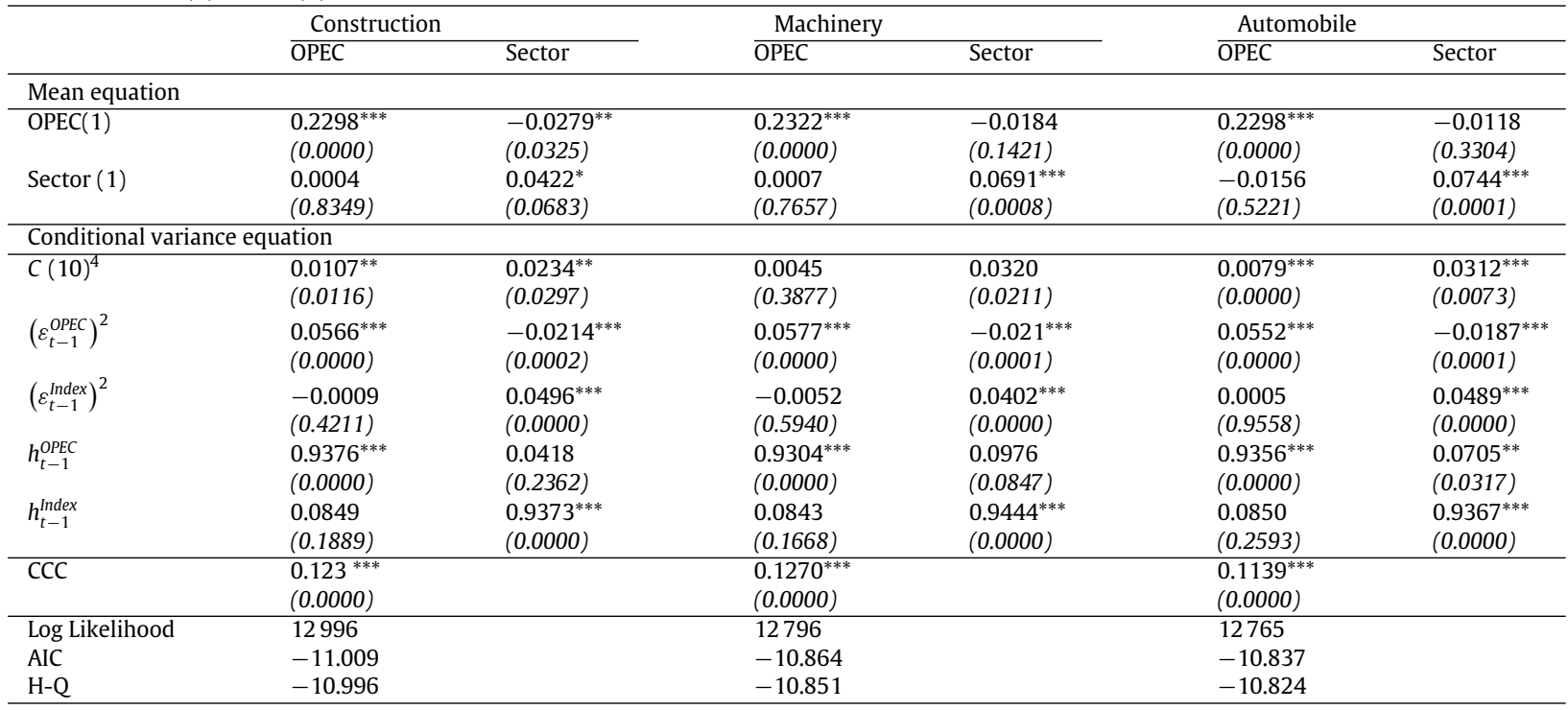

Note: The bivariate $\operatorname{VAR}(1)-\operatorname{GARCH}(1,1)$ model is estimated for each sector from 2004 to 2014 . The lag order for the VAR model is selected using the AIC and SIC information criteria. *, ** and ${ }^{* * *}$ denote significance levels of $10 \%, 5 \%$ and $1 \%$, respectively. The $p$-values are given in parentheses.

the causality is unidirectional from Machinery and Financial indices to OPEC oil. However, the magnitude of the causality from Machinery is not very strong. The null hypothesis of Machinery does not Granger cause OPEC oil is rejected at a $10 \%$ significance level. Further, Financials does not Granger cause OPEC oil is rejected at a 5\% significance level. Interestingly, there is no significant causality reported from OPEC oil to any Chinese sectoral indices.

The results of the bivariate VAR-GARCH model for the Construction, Machinery and Automobile sectors are given in Table 5. The results show that one-period lagged oil and sectoral stock indices, denoted by OPEC (1) and Sector (1), this affects their own values significantly. This also suggests short-term price predictability both in oil and in the sectors of Construction, Machinery and Automobile. In particular, the magnitudes of short-term predictability in stock price changes are strong for the Machinery, and Automobile sectors. The findings are consistent with the recent papers of Arouri et al. [10] and Lin et al. [18].

The estimates of the ARCH and GARCH coefficients, which capture shocks and volatility persistence in the conditional variance, are statistically significant. The terms $h_{t-1}^{\text {OPEC }}$ and $h_{t-1}^{\text {Index }}$ denote conditional variances for OPEC oil and the Chinese sectoral stock indices at time $t$, respectively. The error terms, $\left(\varepsilon_{t-1}^{O P E C}\right)^{2}$ and $\left(\varepsilon_{t-1}^{\text {Index }}\right)^{2}$, represent the effect of the news (unexpected shocks) on OPEC oil and the Chinese stock market, respectively, at time $t-1$.

The findings present that past oil shocks have significant impact on the conditional volatility of stock indices for Construction, Machinery, and Automobile. The sign of the impact is negative and the level of significance is $1 \%$. This implies that past oil shocks affect the sectoral stock returns negatively. As for the opposite direction, the impact of past sectoral stock indices on the conditional volatility of oil is insignificant. Considering the volatility spillover effects, the spillover from oil to the Automobile sector appears to be significant at 5\% level. For the Construction and Machinery sectors, there are no significant volatility spillover effects from oil to these sectors. The findings show that a $1 \%$ increase in the volatility of OPEC oil will cause the Automobile stock index to move $7.05 \%$ in the same direction as the OPEC oil. However, a movement of a $1 \%$ volatility of any sectoral stock index has no significant impact on OPEC oil. This result suggests that the conditional volatility of oil is only driven by its own past news and volatility. Arouri et al. [10] also find similar results for the European 
Table 6

Estimates of VAR(1)-GARCH(1) model for OPEC oil and sectoral stock returns.

\begin{tabular}{|c|c|c|c|c|c|c|}
\hline & \multicolumn{2}{|l|}{ Military } & \multicolumn{2}{|c|}{ Agriculture } & \multicolumn{2}{|c|}{ Financials } \\
\hline & $\overline{\mathrm{OPEC}}$ & Sector & $\overline{\mathrm{OPEC}}$ & Sector & $\overline{\mathrm{OPEC}}$ & Sector \\
\hline \multicolumn{7}{|l|}{ Mean equation } \\
\hline \multirow[t]{2}{*}{ OPEC(1) } & $0.2216^{* * *}$ & 0.0036 & $0.2303^{* * *}$ & -0.0135 & $0.2356^{* * *}$ & $-0.0302^{* *}$ \\
\hline & $(0.0000)$ & $(0.7292)$ & $(0.0000)$ & $(0.2414)$ & $(0.0000)$ & $(0.0046)$ \\
\hline \multirow[t]{2}{*}{ Sector (1) } & 0.0009 & $0.0833^{* * *}$ & 0.0028 & $0.0901^{* * *}$ & 0.0352 & -0.0002 \\
\hline & $(0.9741)$ & $(0.0001)$ & $(0.9056)$ & $(0.0000)$ & $(0.2522)$ & $(0.9901)$ \\
\hline \multicolumn{7}{|c|}{ Conditional variance equation } \\
\hline \multirow[t]{2}{*}{$C(10)^{4}$} & -0.0037 & $0.1632)^{* * *}$ & $0.0070^{*}$ & $0.0379^{* * *}$ & $0.0081^{* *}$ & $0.0296^{* * *}$ \\
\hline & $(0.5421)$ & $(0.0019)$ & $(0.0702)$ & $(0.0061)$ & $(0.0250)$ & $(0.0010)$ \\
\hline \multirow{2}{*}{$\left(\varepsilon_{t-1}^{O P E C}\right)^{2}$} & $0.0506^{* * *}$ & $-0.0148^{* * *}$ & $0.0545^{* * *}$ & $-0.0216^{* * *}$ & $0.0554^{* * *}$ & -0.0056 \\
\hline & $(0.0000)$ & $(0.0002)$ & $(0.0000)$ & $(0.0000)$ & $(0.0000)$ & $(0.1884)$ \\
\hline \multirow{2}{*}{$\left(\varepsilon_{t-1}^{\text {Index }}\right)^{2}$} & $-0.0335^{*}$ & $0.0759^{* * *}$ & -0.0079 & $0.0613^{* * *}$ & -0.0043 & $0.0316^{* * *}$ \\
\hline & $(0.0818)$ & $(0.0000)$ & $(0.5117)$ & $(0.0000)$ & $(0.6684)$ & $(0.0000)$ \\
\hline \multirow[t]{2}{*}{$h_{t-1}^{O P E C}$} & $0.9352^{* * *}$ & 0.1633 & 0.9374 & 0.0801 & 0.9286 & $0.0704^{* *}$ \\
\hline & $(0.0000)$ & $(0.0381)$ & $(0.0000)$ & $(0.0733)$ & $(0.0000)$ & $(0.0293)$ \\
\hline \multirow{2}{*}{$h_{t-1}^{\text {Index }}$} & 0.2855 & $0.8826^{* * *}$ & 0.0874 & $0.9255^{* * *}$ & 0.0023 & $0.9638^{* * *}$ \\
\hline & $(0.1624)$ & $(0.0000)$ & $(0.3017)$ & $(0.0000)$ & $(0.9553)$ & $(0.0000)$ \\
\hline \multirow[t]{2}{*}{$\mathrm{CCC}$} & $0.0816^{* * *}$ & & $0.0954^{* * *}$ & & $0.1317^{* * *}$ & \\
\hline & $(0.0000)$ & & $(0.0000)$ & & $(0.0000)$ & \\
\hline Log Likelihood & 12399 & & 12759 & & 12239 & \\
\hline AIC & -10.527 & & -10.832 & & -10.390 & \\
\hline $\mathrm{H}-\mathrm{Q}$ & -10.513 & & -10.819 & & -10.377 & \\
\hline
\end{tabular}

Note: The bivariate VAR(1)-GARCH $(1,1)$ model is estimated for each sector. The lag order for the VAR model is selected using the AIC and SIC information criteria. ${ }^{*},{ }^{* *}$, and ${ }^{* * *}$ denote significance levels of $10 \%, 5 \%$ and $1 \%$, respectively. The $p$-values are given in parentheses.

sectoral stocks. They argue that volatility transmission runs more often from oil market to stock sectors rather than from stock sectors to oil market.

As a matter of fact, China heavily depends on oil for its development. The industries such as machinery, automobile, construction and agriculture have a high dependence on oil. Therefore, the companies in these industries should develop hedging strategies against changes in oil prices. However, in China there appears to be no bilateral spillover between oil and sectoral stock indices. As a result, in this case, the hedging strategies seem to be not very effective. This situation can be attributed to the nature of the Chinese stock market. In China, individual investors dominate the stock markets and the government heavily regulates the stock markets in order to protect investors against huge fluctuations. For instance, foreign investors are not allowed to trade shares of local Chinese companies (so called A-shares). Only qualified foreign institutional investors, who have special permission from Chinese authorities, can trade A-shares. These types of regulations can weaken the volatility spillover effects from the stock market to the oil market.

Regarding estimates of the Constant Conditional Correlation (CCC), the findings present that there is a relatively low and positive correlation between OPEC oil and sectoral stock indices. While the lowest correlation occurs between oil and the Automobile sector, the highest correlation emerges between oil and the Machinery sector.

The results of the bivariate VAR-GARCH model for Military, Agriculture, and Financials are given in Table 6. The findings show that with the exception of Financials, the one-period lagged stock returns of the Military and Agriculture sectors affect their current values. This implies short-term predictability in these sectoral stock returns.

Moreover, the findings show that the conditional volatility of oil returns is significantly affected by the unexpected changes in the oil market, $\left(\varepsilon_{t-1}^{O P E C}\right)^{2}$. While past oil shocks have had a positive impact on the current volatility of oil, the impacts of past oil shocks on sectoral stock indices (namely on Military and Agriculture) are negative. There is no significant impact of past oil shocks on Financials.

When we attempt to highlight the volatility spillovers between oil and the sectoral stock indices, the findings suggest that the past conditional volatility of oil $\left(h_{t-1}^{\text {OPEC }}\right)$ has significant impact only on Financials. The movement of $1 \%$ volatility in the oil market pushes the Financials index in the same direction by $7.04 \%$. This volatility relationship is not surprising. Oil price shocks affect not only investors' demand for financial products and services but also financial institutions' profitability through lending activities. High oil prices may result in high domestic demand, high lending activities and high repayment rates. This situation is even more obvious in the case of China. The reason is that banks dominate the Chinese financial system and provide the majority of total credit to the private sector. The banking industry is highly concentrated and the government plays a crucial role in directing the activities of banks.

As for the opposite direction, the impact of past sectoral stock volatility, $h_{t-1}^{\text {STOCK }}$, on the conditional volatility of OPEC oil is statistically insignificant in all cases. This is consistent with the findings of Arouri et al. [10].

The findings further show that the CCC between oil and sectoral stock indices are positive and significant. The correlation levels are relatively high for Machinery (12.7\%) and Finance sectors (13.17\%), respectively. This result is consistent with the findings of Granger causality test results reported in Table 4. The Granger test results indicate unidirectional causality from oil to these two sectors. 
Table 7

Portfolio optimal weights and hedge ratios.

\begin{tabular}{lll}
\hline Portfolio & $w_{t}^{\text {Index,OPEC }}$ & $\beta_{t}^{\text {Index, OPEC }}$ \\
\hline Construction-OPEC & 0.3449 \\
Machinery-OPEC & 0.3074 \\
Military-OPEC & 0.2611 \\
Automobile-OPEC & 0.3095 \\
Agriculture-OPEC & 0.0947 \\
Financials-OPEC & 0.0525 \\
\hline
\end{tabular}

Note: The table reports optimal weights of oil and hedge ratios for an oil-stock portfolio.

In general, the correlation levels are relatively weak for Military, and Agriculture. The low correlations between oil and sectoral stock returns can help investors to design their portfolios. In particular, the lowest CCC estimate for the Military sector suggests that investing in Military stocks may provide opportunity to investors to diversify their risks in their oilstock portfolio holdings and have efficient risk management. The strong presence of the Chinese government in the military industry can explain the low correlation between OPEC oil and military stocks. In China, the military stock index includes defense companies as well as subsidiaries of defense companies. Aerospace and shipbuilding companies are also considered as military-sector players and many of these companies are A-shares. In other words, the number of stocks available for foreign investors is less than half of the total military companies listed on the Shanghai and Shenzen Stock Exchanges. In addition to this, the stock prices of the military industry are very sensitive to the military budget and strength of China. While the investors of this sector enjoy their returns when regional tensions escalate, military companies enjoy their profits when the central government prioritizes the sector.

\subsection{Portfolio management and hedging strategies}

As discussed above, the findings of the VAR (1)-GARCH (1) model show a significant volatility spillover between OPEC oil and the Chinese sectoral stock indices. Using estimates from the VAR-GARCH model, we calculate optimal weights and hedge ratios for oil-stock portfolios. To illustrate this scenario, suppose that an investor holds a set of stocks and attempts to hedge his stock position. The objective of the investor is to offset the risk without reducing the expected return. According to Kroner and $\mathrm{Ng}$ [56], the optimal weight of oil in a one-dollar stock-oil portfolio at time $t$ is given as:

$$
W_{t}^{\text {Index }, \text { OPEC }}=\frac{h_{t}^{\text {Index }}-h_{t}^{\text {Index }, \text { OPEC }}}{h_{t}^{\text {Index }}-2 h_{t}^{\text {Index }, \text { OPEC }}+h_{t}^{\text {OPEC }}}
$$

and

$$
\begin{cases}W_{t}^{\text {Index,OPEC }} & 0 \text { if } W_{t}^{\text {Index }, \text { OPEC }}<0 \\ & \text { if } 0 \leq W_{t}^{\text {Index }, \text { OPEC }} \leq 1 \\ & 1 \text { if } W_{t}^{\text {Index }, \text { OPEC }}>1\end{cases}
$$

where $W_{t}^{\text {Index,OPEC }}$ refers to the weight of OPEC oil in a one-dollar portfolio of the two assets defined at time $t$. The values of $h_{t}^{\text {Index }}$ and $h_{t}^{\text {OPEC }}$ are conditional variances of the sectoral stock indices and OPEC oil, respectively. The value of $h_{t}^{\text {Index,OPEC }}$ refers to the conditional covariance between oil and sectoral stock market returns at time $t$. The weight of the sectoral stock index in an oil-stock portfolio is obtained by calculating $\left(1-W_{t}^{\text {Index,OPEC }}\right)$.

In order to calculate the optimal hedge ratio, we follow the method proposed by Kroner and Sultan [57]. It is important to specify how much a long position (buy) of one dollar in the stock market should be hedged by a short (sell) position of $\beta_{t}$ dollar in the oil market. The hedge ratio is calculated as follows:

$$
\beta_{t}^{\text {Index }, \text { OPEC }}=\frac{h_{t}^{\text {Index, OPEC }}}{h_{t}^{\text {Index }}}
$$

Table 7 presents the optimal weights, $W_{t}^{\text {Index,OPEC }}$, and hedge ratios, $\beta_{t}^{\text {Index, OPEC }}$, for oil-stock portfolios including OPEC oil and the Chinese sector index. The optimal weights of oil suggested by the VAR-GARCH model are $34.49 \%$ for Construction, $30.74 \%$ for Machinery, 26.11\% for Military, 30.95\% for Automobile, 31.76\% for Agriculture, and $21.28 \%$ for Financials. The findings suggest that the majority of money should be invested in stock market indices. For example, in a one-dollar portfolio, the optimal allocation for oil is 34.49 cents and the remainder, 65.51 cents, should be invested in the sectoral stock market index.

The findings further show that hedge ratios are generally low for each portfolio. This implies that under the VAR-GARCH framework, less oil assets are required to minimize the risk for investors with stock holdings. The hedge ratios range from $5.25 \%$ in the Military-OPEC portfolio to $10.01 \%$ in the Construction-OPEC portfolio. For example, a $10.01 \%$ hedge ratio in a Construction-OPEC portfolio suggests that a one-dollar long (buy) position in the Construction index should be shorted (sell) by 10.01 cents of oil. 


\section{Conclusion}

This paper examines the volatility spillover effects between OPEC oil and sectoral stock returns in China. We use the daily closing prices of six sectoral stock indices: Construction, Machinery, Military, Automobile, Agriculture, and Financials. None of the sectoral stock indices used in this paper has been analyzed in previous studies. Our analysis is based on the VAR-GARCH method, developed by Ling and McAleer [17]. In the light of the obtained results, we further calculate the optimal portfolio weights and hedge ratios for the portfolios including OPEC oil and Chinese sectoral stock indices.

The findings show significant volatility spillover between OPEC oil and the Chinese sectoral stock indices. The transmission of volatility is more apparent from oil to stock returns rather than sectoral stocks to oil. This finding can be attributed to the nature of the Chinese stock markets, where the observed spillover effects mainly come from past shocks. The past oil shocks have had negative and significant impacts on the conditional volatility of Construction, Machinery, Automobile, Military, and Agriculture stock indices. With the exception of the Military stock index, there is no significant impact of the past stock return shocks on the volatility of oil returns. This result can be attributed to the nature of Chinese stock markets. There exists a strong presence of central government in the economy and the stock markets are subject to several regulations including the restriction on stock purchases by foreign investors. These regulations affect the degree of market openness and weaken the volatility spillover effects from stock markets to other markets. However, the spillover effects would become significant with increasing market reforms and financial liberalization in China.

Among all sector indices, the military index has the lowest correlation with OPEC oil. This finding can be attributed to the strong presence of the Chinese government in the military industry. Major military companies are state-owned group companies and less than half of the military stocks are available to foreign investors. For portfolio investors, with military stocks having the lowest constant correlation with OPEC oil, this could be an opportunity for portfolio diversification and efficient risk management.

Furthermore, the examination of optimal weights and hedge ratios suggest that the optimal portfolios should have stocks that outweigh oil assets. The risk in stock investment can be hedged by taking a short position in the oil market. Our findings for optimal hedge ratios are in line with the previous studies, in that oil can be an integral part of a diversified portfolio of stocks and it can help to hedge risk effectively.

Understanding the behavior of volatility in oil and sector-specific stock index prices has important implications for investors and policymakers. Considering investors who hold different sectoral stocks and oil in their portfolios, the results suggest that investors should monitor the correlation levels between sectoral stock returns and oil. In particular, investors should develop their investment strategies according to unidirectional volatility spillover from oil to stock returns. Further, it would be interesting to extend this study to allow an examination of the volatility spillover between stock markets and other major energy commodities such as coal and natural gas.

\section{References}

[1] J. Hamilton, Oil and the macroeconomy since World War II, J. Polit. Econ. 91 (2) (1983) 228-248.

[2] K. Mork, Oil and the macroeconomy when prices go up and down: An extension of Hamilton's results, J. Polit. Econ. 97 (1989) $740-744$.

[3] R. Huang, R. Masulis, H. Stoll, Energy shocks and financial markets, J. Futures Mark. 16 (1996) 1-27.

[4] N. Apergis, S.M. Miller, Do structural oil-market shocks affect stock prices? Energy Econ. 31 (2009) 569-575.

[5] J.I. Miller, R.A. Ratti, Crude oil and stock markets: stability, instability and bubbles, Energy Econ. 31 (2009) 559-568.

[6] C.M. Jones, G. Kaul, Oil and stock markets, J. Finance 51 (1996) 463-491.

[7] P. Sadorsky, Oil price shocks and stock market activity, Energy Econ. 21 (1999) 449-469,

[8] L. Kilian, C. Park, The impact of oil price shocks on the US stock market, Internat. Econom. Rev. 50 (2009) 1267-1287.

[9] S.S. Chen, Do higher oil prices push the stock market into bear territory? Energy Econ. 32 (2010) 490-495.

[10] M. Arouri, J. Jouini, D.K. Nguyen, On the impacts of oil price fluctuations on european equity markets: volatility spillover and hedging effectiveness, Energy Econ. 34 (2012) 611-617.

[11] A. Dorsman, A. Koch, M. Jager, A. Thbeault, Adding Oil to a Portfolio of Stocks and Bonds? in: A. Dorsman, J.L. Simpson, W. Westman (Eds.), Energy Economics and Financial Markets, Springer, 2013, pp. 197-214.

[12] K. Koyoma, Oil market in China: current situation and future prospects, The Institute of Energy Economics, Working Paper, Japan, 2002.

[13] U.S. Energy Information Administration, Assumptions to the Annual Energy Outlook Washington, DC, 2015.

[14] C. Feng, Embracing Interdependence: The Dynamics of China and Middle East, The Brook Brookings Institution, 2015.

[15] M. Lanteigne, Chinese Foreign Policy: An Introduction, Routledge, London, 2013.

[16] G. Caporale, D. Ciferri, A. Girardi, Oil price uncertainty and sectoral stock returns in China: China Economic Review, China Econ. Rev. 34 (2015) 311-321.

[17] S. Ling, M. McAleer, Asymptotic theory for a vector ARMA-GARCH model, Econometric Theory 19 (2003) 278-308.

[18] B. Lin, W.K. Presley, A.O. Micheal, Oil price fluctuation, volatility spillover and the Ghanaian equity market: Implication for portfolio management and hedging effectiveness, Energy Econ. 42 (2014) 172-182.

[19] S. Hammoudeh, Y. Yuan, M. McAleer, M.A. Thompson, Precious metals-exchange rate volatility transmissions and hedging strategies, Int. Rev. Econ. Finance 19 (2010) 633-647.

[20] J.D. Elliott, K. Yan, The Chinese Financial System An Introduction and Overview, China Center at Brookings, 2013.

[21] M. Deweaver, Betting on China’s Military Buildup, Research Paper, Quantrarian Capital Management, 2016.

[22] M.M. Hutchison, Structural change and the macroeconomic effects of oil shocks: empirical evidence from the United States and Japan, J. Int. Money Finance 12 (6) (1993) 587-606.

[23] R.B. Barsky, L. Kilian, Oil and the macroeconomy since the 1970s, J. Econ. Perspect. 18 (4) (2004) 115-134.

[24] A. Cologni, M. Manera, Oil prices, inflation and interest rates in a structural cointegrated VAR model for the G-7 countries, Energy Econ. 30 (2008) $856-888$

[25] J.L. Kling, Oil price shocks and stock-market behavior, J. Portfolio Manag. 12 (1985) 34-39.

[26] E. Papapetrou, Oil price shocks, stock market, economic activity and employment in Greece, Energy Econ. 23 (2001) 511-532. 
[27] S.A. Basher, P. Sadorsky, Oil price risk and emerging stock markets, Glob. Finance J. 17 (2006) 224-251.

[28] J. Park, R.A. Ratti, Oil price shocks and stock markets in the U.S. and 13 European countries, Energy Econ. 30 (2008) $2587-2608$.

[29] P.K. Narayan, S. Narayan, Modeling the impact of oil prices on Vietnam's stock prices, Appl. Energy 87 (1) (2010) $356-361$.

[30] Y.H. Lee, J. Chiou, Oil sensitivity and its asymmetric impact on the stock market, Energy 36 (1) (2011) $168-174$.

[31] R. Jammazi, Cross dynamics of oil-stock interactions: A redundant wavelet analysis, Energy 44 (2012) $750-777$.

[32] M. Liu, Q. Ji, F. Fan, How does oil market uncertainty interact with other markets? An empirical analysis of implied volatility index, Energy 55 (2013) 860-868.

[33] F. Malik, B.T. Ewing, Volatility transmission between oil prices and equity sector returns, Int. Rev. Financ. Anal. 18 (2009) 95-100.

[34] M. Arouri, A. Lahiani, D.K. Nguyen, Return and volatility transmission between world oil prices and stock markets of the GCC countries, Econ. Model. 28 (2011) 1815-1825.

[35] P. Sadorsky, Correlations and volatility spillovers between oil prices and the stock prices of clean energy and technology companies, Energy Econ. 34 (2012) 248-255.

[36] B. Awartani, I.A. Maghyereh, Dynamic spillovers between oil and stock markets in the Gulf Cooperation Council Countries, Energy Econ. 36 (2013) $28-42$.

[37] B. Fowowe, Jump dynamics in the relationship between oil prices and the stock market: evidence from Nigeria, Energy 56 (2013) $31-38$.

[38] J. Jouini, Return and volatility interaction between oil prices and stock markets in Saudi Arabia, J. Policy Model. 35 (2013) $1124-1144$.

[39] W. Mensi, S. Hammoudeh, K.D. Nguyen, S. Min-Yoon, Dynamic spillovers among major energy and cereal commodity prices, Energy Econ. 43 (2014) $225-243$.

[40] E. Bouri, Return and volatility linkages between oil prices and the Lebanese stock market in crisis periods, Energy 89 (2015) 365-371.

[41] C.C. Nguyen, M.I. Bhatti, Copula model dependency between oil prices and stock markets: Evidence from China and Vietnam, J. Int. Financ. Mark. Inst. \& Money 22 (2012) 758-773.

[42] X. Wen, Y. Wei, D. Huang, Measuring contagion between energy market and stock market during financial crisis: A copula approach, Energy Econ. 34 (5) (2012) 1435-1446.

[43] Y. Wang, C. Wu, L. Yang, Oil price shocks and stock market activities: Evidence from oil-importing and oil-exporting countries, J. Comp. Econ. 41 (4) (2013) 1220-1239.

[44] C.R. Fang, S.Y. You, The impact of oil price shocks on the large emerging countries' stock prices: Evidence from China, India and Russia, Int. Rev. Econ. Finance 29 (2014) 330-338.

[45] D.C. Broadstock, Y. Fan, Q. Ji, D. Zhang, Shocks and stocks: A bottom-up assessment of the relationship between oil prices, gasoline prices and the returns of Chinese firms, Energy J. 37 (SI1) (2016) 55-86.

[46] R.G. Cong, Y.M. Wei, J.L. Jiao, Y. Fan, Relationships between oil price shocks and stock market: An empirical analysis from China, Energy Policy 36 (9) (2008) 3544-3553.

[47] C. Zhang, X. Chen, The impact of global oil price shocks on China's stock returns: Evidence from the ARJI(-ht)-EGARCH model, Energy 36 (2011) 6627-6633.

[48] C.L. Chang, M. McAleer, R. Tansuchat, Conditional correlations and volatility spillovers between crude oil and stock index returns, N. Am. J. Econ. Finance 25 (2013) 116-138.

[49] S.F. Li, H.M. Zhu, K. Yu, Oil prices and stock market in China: A sector analysis using panel cointegration with multiple breaks, Energy Econ. 34 (2012) 1951-1958.

[50] S. Hammoudeh, R. Sari, B. Ewing, Relationships among strategic commodities and with financial variables: a new look, Contemp. Econ. Policy 27 (2009) 251-269.

[51] T. Bollerslev, Modeling the coherence in short-run nominal exchange rates: a multivariate generalized ARCH approach, Rev. Econ. Stat. 72 (3) (1990) 498-505.

[52] J.M. Lombardi, F. Ravazzolo, On the correlation between commodity and equity returns: implications for portfolio allocation, BIS Working Papers, No: $420,2013$.

[53] D. Dickey, W. Fuller, Distribution of the estimators for autoregressive time series with a unit root, J. Amer. Statist. Assoc. 74 (1979) $427-431$.

[54] P. Philips, P. Perron, Testing for unit roots in time series regression, Biometrika 75 (1988) 335-346.

[55] D. Kwiatkowski, P.C.B. Phillips, P. Schmidt, Y. Shim, Testing the null hypothesis of stationarity against the alternative of a unit root: how sure are we that economic time series are non-stationary? J. Econometrics 54 (1992) 159-178.

[56] K.F. Kroner, V.K. Ng, Modeling asymmetric comovements of asset returns, Rev. Financ. Stud. 11 (1998) $817-844$.

[57] K.F. Kroner, J. Sultan, Time dynamic varying distributions and dynamic hedging with foreign currency futures, J. Financ. Quant. Anal. 28 (1993) 535551.

\section{Further Reading}

[1] R.F. Engle, Dynamic conditional correlation: a simple class of multivariate generalized autoregressive conditional heteroskedasticity models, J. Bus. Econom. Statist. 20 (2002) 339-350. 